\title{
New options in insulin therapy
}

\section{Helena Schmid*}

\begin{abstract}
Objective: To review the new options in insulin therapy for controlling diabetes mellitus in children and adolescents.

Sources: Articles indexed in PubMed were located using the search terms insulin analogs in children and adolescents and reviewed. Information was also obtained from American Diabetes Association and Sociedade Brasileira de Diabetes consensus documents.

Summary of the findings: Information is presented on new analogs of insulin and, for purposes of comparison, the other insulin modalities currently available are also reviewed, focusing on insulin therapies which attempt to approximate basal-bolus treatment strategies to physiology. With the objective of obtaining improved metabolic control, more and more children are being put on multiple daily injection regimes or using continuous subcutaneous insulin infusion. It is difficult to achieve optimum glycemic control in children due to the increased risk of hypoglycemia resulting from the great variability in dietary intake habits and in physical activity levels. With diabetes type 1 , if rapid-acting analogs are given subcutaneously in bolus, they generally reduce hypoglycemia episodes and postprandial glycemia levels, compared with regular human insulin, while basal analogs tend to reduce particularly the number of episodes of nocturnal hypoglycemia.
\end{abstract}

Conclusions: Although the benefits to individual metabolic and clinical outcomes appear modest, the majority of studies demonstrate benefits when insulin analogs are used in the treatment of diabetes type 1 or 2 .

J Pediatr (Rio J). 2007;83(5 Suppl):S146-154: Diabetes mellitus, insulin analogs, infusion pumps, monitoring.

\section{Introduction}

In 1993, the results of the Diabetes Control and Complications Trial (DCCT $)^{1,2}$ revolutionized the treatment of diabetes mellitus type 1 (T1DM), demonstrating the importance of aiming at lower glycemic levels than those generally obtained and of maintaining glycosylated hemoglobin (HbA1c) levels as close as possible to normal. The study proved that intensive treatment of T1DM, with three or more doses of different types of insulin with differing actions, is effective for controlling the chronic complications of diabetes mellitus (DM), since it detected a $76 \%$ reduction in cases of retinopathy, $60 \%$ fewer cases of neuropathy and $39 \%$ less nephropathies among patients treated intensively in relation to those treated conventionally. Since there was this difference in the incidence rate of the chronic microangiopathic complications of DM, this was interpreted as being caused by better metabolic control, since these patients' glycated hemoglobin levels were statistically lower $(8.05 \%)$ than those of patients treated conventionally $(9.76 \%)$. For this reason, when the DCCT was completed, it was suggested that all patients should continue in another study, named Epidemiology of Diabetes Interventions and Complications (EDIC). In this study, all patients were given intensive treatment and, specifically in the subset of adolescents (13 to 17 years), the degree of metabolic control did not vary statistically when those who had been intensively treated on the DCCT and those who had received conventional treatment were compared ( $\mathrm{HbA} 1 \mathrm{c}$ of $8.38 \%$ vs. $8.45 \%)$. When the frequency of progression to diabetic retinopathy and nephropathy was evaluated, it was observed that the group that had been treated intensively for longer (since the start of the DCCT) continued to have a lower frequency of progression to diabetic retinopathy and nephropathy, suggesting that the attempts to achieve better glycemic control

* Doutora. Professora titular, Programa de Pós Graduação em Ciências Médicas, Fundação Faculdade Federal de Ciências Médicas de Porto Alegre (FFFCMPA), Porto Alegre, RS, Brazil.

Suggested citation: Schmid H. New options in insulin therapy. J Pediatr (Rio J). 2007;83(5 Suppl):S146-154.

doi $10.2223 / J P E D .1712$ 
must begin early on in the course of T1DM. ${ }^{2}$ Furthermore, 12 years after the end of the DCCT, the results of the EDIC demonstrated a reduction of 40 to $60 \%$ in macrovascular events among the intensively treated cohort compared with the less intensively treated group. ${ }^{3}$ Both studies had evidence level 1 and recommendation grade $A$ for intensive insulin treatment in T1DM. Intensive treatment with insulin is therefore recommended for all children, but successfully carrying out this treatment remains a challenge: if factors relating to compliance with treatment and with inadequate family support are excluded, hypoglycemia continues to be the factor limiting the attainment of ideal glycemic control. ${ }^{4,5}$

More recent advances in insulin therapy help us to meet the challenge of carrying out the intensive diabetes treatments recommended by the results of the DCCT, EDIC and other similar studies. In this review article we present the types of insulin available and the methods for administering them in order to provide this intensive treatment in accordance with the requirements of each child or adolescent.

On the other hand, several different studies have consistently demonstrated that the frequency of glycemic selfmonitoring has an inverse relationship with $\mathrm{HbA1c}$, i.e., a positive relationship with better glycemic control.

Target glucose and $\mathrm{HbA} 1 \mathrm{c}$ levels recommended by the American Diabetes Association ${ }^{4}$ should be established for children and adolescents according to age group (Table 1 ). The International Society for Pediatric and Adolescent Diabetes (ISPAD) recommends that glycated hemoglobin should be kept below $7.6 \% .^{3}$

Since monitoring of blood glucose is an essential component of intensive insulin treatment, we will also present new technological advances in the field of continuous glycemia monitoring, which will improve intensive diabetes treatment and will probably also support the development of a closedloop insulin delivery system.

\section{Types of insulin and their uses with children being treated intensively}

\section{Rapid-acting analogs and regular insulin}

Rapid-acting types of insulin (soluble and regular), in combination with intermediate-action insulin, administered in two, or preferably three, daily doses are still used today as essential components of the majority of insulin replacement regimes in many parts of the world (Table 2).

Short-acting insulin reaches peak activity later than do the new rapid-acting analogs and to achieve optimal activity it must be administered at least 30 minutes before meals. It is, consequently, inflexible and inconvenient to use, especially with children. On the other hand, compared with the new analogs, its action is longer lasting: this allows a patient to eat a snack in the middle of the morning or afternoon, without an additional injection, making it a more attractive option in some circumstances, where the aim is to intensify treatment. It is, however, important to remember that this advantage of regular insulin must be balanced against the finding that there is an increased risk of hypoglycemia.

Rapid-acting analogs insulin lispro (ILis; HumaLog1, Eli Lilly) and insulin aspart (IAsp; NovoRapid1, Novo Nordisk) were the first to be used. More recently, a third rapid-acting analog was cleared for use in the United States - insulin glulisine (IGlu; ApidraTM, Sanofi-Aventis). In relation to human insulin, rapid-acting analogs break down in the subcutaneous tissues immediately after injection so that their onset of action is also faster, with a higher peak level in serum (Table 2).

The first rapid-acting insulin analog became available in 1996 and other rapid-acting analogs have being developed since then. They have been created by a variety of modifications to the chemical structure of the human insulin protein, substituting several amino acids in different positions, with the intention of bringing forward onset and shortening duration of action when compared with regular/soluble insulin. Analogs have this effect because, after injection into subcutaneous tissue, the proportion that is bound in the form of dimers and hexamers is lower, which means that the monomeric analog molecule can be absorbed at the point of injection more quickly. Although they have different chemical structures, no significant differences have been reported between them in terms of onset or duration of action. Administration 5-15 minutes before a meal has a greater impact on increase in post-prandial glucose (PPG), when compared with regular human insulin, with patients on analogs having levels

Table 1 - Target glucose and HbA1c levels in plasma for T1DM patients, by age group

\begin{tabular}{lccc}
\hline & \multicolumn{2}{c}{ Plasma glucose $\mathbf{( m g / d L )}$} & HbA1c \\
\hline Values by age group & Before meals & Before going to bed & $<8.5$ and $>7.5 \%$ \\
$\begin{array}{l}\text { Toddlers and preschool aged } \\
\text { children }\end{array}$ & $100-180$ & $110-200$ & $<\%$ \\
School aged children & $90-180$ & $100-180$ & $<7.5 \%$ \\
Adolescents and young adults & $90-130$ & $90-150$ &
\end{tabular}

Adapted from American Diabetes Association. ${ }^{4}$ 
Table 2 - Types of insulin and their actions

\begin{tabular}{|c|c|c|c|}
\hline Type of insulin & Onset of action & Peak of action & Total duration \\
\hline \multicolumn{4}{|l|}{ Short and rapid action } \\
\hline Regular & 30-60 minutes & $2-4 h$ & $6-9 h$ \\
\hline Aspart, lispro, glulisine & $10-15$ minutes & $30-90$ minutes & $3-4 h$ \\
\hline \multicolumn{4}{|l|}{ Intermediate action } \\
\hline $\mathrm{NPH}$ & $1-2 \mathrm{~h}$ & $3-8 h$ & $12-15 \mathrm{~h}$ \\
\hline \multicolumn{4}{|l|}{ Basal insulin } \\
\hline Glargine & $1-2 \mathrm{~h}$ & no peak & $24 \mathrm{~h}$ \\
\hline Detemir & $1-2 \mathrm{~h}$ & no peak & $24 \mathrm{~h}$ \\
\hline \multicolumn{4}{|l|}{ Premixed insulin } \\
\hline 70/30 NPH/regular & $30-60$ minutes & $3-8 h$ & $12-15 \mathrm{~h}$ \\
\hline 75/25 NPH/lispro & $10-15$ minutes & $30 \mathrm{~min}-8 \mathrm{~h}$ & $12-15 \mathrm{~h}$ \\
\hline
\end{tabular}

$\mathrm{NPH}=$ neutral protamine Hagedorn. ${ }^{6}$

that are lower by 0.6 to $2.0 \mathrm{mmol} / \mathrm{L} .{ }^{4,5}$ Another advantage of rapid-acting analogs that has been found by some studies is a reduction in the number of episodes of hypoglycemia. ${ }^{7,8} \mathrm{Sev}-$ eral studies undertaken with adults have demonstrated a mild reduction in $\mathrm{HbA} 1 \mathrm{c}$ (20.1 to $20.2 \%$ ) for all three analogs when compared with regular insulin, but studies undertaken with children did not detect significant differences. ${ }^{9}$

With small children the quantity of food that will be ingested at each meal is often highly unpredictable, which makes the use of preprandial rapid-acting insulin a cause for concern, whenever the child does not consume the quantity that was calculated for that dose of insulin. Therefore, in certain situations it is safer to administer ultra-rapid insulin after the meal, when the quantity that the child has consumed is already known. Jovanovic studied the glycemic profile when aspart insulin was given before or soon after meals and concluded that it was better when administered before the meal. ${ }^{10}$ Nevertheless, each case should be assessed individually and, very often, children whose feeding habits are highly unpredictable will benefit from post-prandial insulin.

Although a recent meta-analysis suggested that shortacting analogs offer only a small advantages in terms of $\mathrm{HbA} 1 \mathrm{c}$ and no advantages in terms of hypoglycemia, it is important to take into consideration that the majority of the studies included in the meta-analysis were not designed to demonstrate the superiority of insulin analogs over human insulin, but their equivalence and that, in some of these studies, $\mathrm{HbA1c}$ was a secondary outcome. Furthermore, there was a great variation between the studies in terms of the populations investigated, patient follow-up and therapeutic strategies. $^{8}$
There is strong evidence that PPG is a direct and independent risk factor for cardiovascular disease, irrespective of fasting plasma glucose and Hba1c. A prospective study has suggested that, in T2DM, a reduction in PPG is associated with a reduction in cardiovascular risk. Therefore, the reductions in PPG observed with the use of rapid-acting analogs may offer significant benefits in terms of future morbidity and mortality. ${ }^{10}$

\section{Intermediate-acting insulin}

The action profile of intermediate-acting insulin makes this type appropriate for regimes where basal insulin is given once to three times a day. The principal preparation currently used with children is neutral protamine Hagedorn (NPH) (Table 2). It has been used at night as nighttime basal insulin. It is more effective for treating diabetes type 2 (T2DM) than for treating children with T1DM. With peak activity occurring 3-8 $\mathrm{h}$ after injection, one dose in the morning may allow children to avoid having to take another insulin injection at lunchtime. However, in order to utilize NPH, a rigid daily nutrition program is needed, including relatively fixed times for meals and snacks with consistent carbohydrate levels. The greatest disadvantages of NPH are the wide daily inter-individual and intraindividual variations in synchronization and duration of peaks, which, when compared with long-acting analogs, may result in less than optimum metabolic control and increased risk of nocturnal hypoglycemia. Lente insulin was used as an intermediate-acting insulin for many years, with a profile of activities similar to that of NPH.

\section{Basal insulin analogs}

Basal insulin analogs have a different mode of action when compared with insulin that exhibits peaks. Two basal insulin 
analogs, glargine insulin (IGlarg; Lantus1, Sanofi-Aventis) and detemir insulin (IDet; Levemir1, Novo Nordisk) are available on the Brazilian and North-American markets. Insulin glargine (IG) is a clear insulin that precipitates in the subcutaneous tissues, after injection, while detemir is an acylated insulin that binds to albumin (Table 1). Although these two basal analogs have not been formally approved in the United States for use with children less than 6 years old, many pediatric diabetes centers have used them with success in these cases. ${ }^{9,11}$ The majority of studies using IG and detemir found reductions in hypoglycemic episodes, particularly of nocturnal hypoglycemia. ${ }^{9,12}$ Basal analogs exhibit a more predictable insulin effect, with lower glycemic variation from one day to another, when compared with NPH insulin. ${ }^{13}$ Glargine insulin became available in 2000. This is a long-acting analog which has a very low peak of activity, with approximately 24 hour duration. The time at which IG is administered does not appear to have any impact whatsoever on its efficacy. ${ }^{14}$ Furthermore, it has proven effective with children and adolescents with poorly controlled T1DM and for reducing hypoglycemic episodes and improving HbA1c levels. ${ }^{15}$ Insulin glargine should be administered at approximately the same time each day in order to maintain its efficacy as a nonpeaking basal insulin. If one dose is missed, $50 \%$ of that day's insulin will be lacking.

Due to its $\mathrm{pH}$ and the solubility properties of IG preparations, the manufacturer's current recommendations require that IG be injected separately from all other insulin preparations, although there is evidence that it can be mixed with lispro and aspart without affecting its effects on glycemia or HbA1c. ${ }^{16,17}$

Insulin Detemir is the newest long-acting analog, with an action that lasts approximately $6-23 \mathrm{~h}$ according to studies undertaken in adults. ${ }^{18}$ The duration of action is dosedependent. If used twice a day, injections offer excellent control, however, one injection per day can be used if the doses are high. Acylation of detemir allows bonding with albumin, which in turn permits the prolonged action. After the injection, insulin detemir forms a liquid deposit in the subcutaneous tissues and then binds with albumin. ${ }^{19}$ Although insulin detemir is soluble at neutral $\mathrm{pH}$, it cannot be mixed with the rapid analogs. Several studies of detemir have demonstrated potential benefits in terms of weight, with weight loss or reduced weight gain in adults ${ }^{19}$ and also in children and adolescents. ${ }^{20}$

\section{Other types of insulin}

\section{Premixed insulin}

Premixed insulin preparations containing a fixed proportion of rapid and intermediate insulin (Table 1). Different proportions of rapid acting insulin and NPH are available in several countries from multiple manufacturers. Although the use of premixed insulin may reduce potential errors preparing insulin syringes, it also removes the flexibility to adjust each type of insulin separately. Premixed insulin does not therefore allow for easy adjustment to account for glycemic variability as foods are absorbed or physical activity carried out; important factors when treating children with T1DM. Premixed insulin can be useful for patients with T2DM, patients who are incapable of learning a more intensive treatment regime or when compliance to insulin treatment is a problem. ${ }^{21}$

\section{Lente, ultralente, and semilente insulin}

The principle manufacturers of lente, ultralente and semilente insulin have recently reduced production, anticipating total discontinuation in the near future. They are not currently available in North America or the majority of Europe and availability is limited in the rest of the world.

Insulin lente has an intermediate action, similar to NPH; semilente is a short-acting insulin and ultralente is a basal insulin, but it is not free from peaks. Ultralente insulin can have an unpredictable activity curve, resulting in unexpected and prolonged hypoglycemia and its use as basal insulin cannot be encouraged. ${ }^{21}$

\section{New methods of insulin administration}

Insulin can be obtained in disposable pens and rechargeable pens, with replacement cartridges. The dose is set by twisting or pressing a button, providing a more convenient administration system and also a system which allows for more exact doses for children, most especially when the dose must be given by people with little knowledge of the problems involved in administering insulin. Some individuals have reported that injections are less painful when pens are used, which may improve compliance with a multiple injection regime. The precision and convenience of these pen devices for injecting insulin have improved the quality of life of patients with T1DM. Insulin pens offer advantages of simplicity, convenience, and, for some patients, increased independence. Some of the most modern pens are capable of storing information on the time of injection and quantity of each insulin dose. The fact that these devices provide a record of insulin doses makes them useful for use with adolescents, who rarely record this information. ${ }^{21}$

\section{Inhaled human insulin}

Inhaled human insulin was recently approved for preprandial use with adult diabetes mellitus patients, but it has not been approved for use with children. This insulin formulation has more rapid onset, but the duration is similar in terms of the glycemic levels obtained with regular insulin given subcutaneously. A meta-analysis carried out by Ceglia et al. ${ }^{22} \mathrm{dem}-$ onstrated a small reduction in $\mathrm{HbA} 1 \mathrm{c}$, favoring subcutaneous insulin when compared with inhaled.

Principal notable side-effects were increased incidence rates of smooth dry nonprogressive coughing and a mild 
reduction in pulmonary function test results [forced expiratory volume in one second (FEV1) and lung carbon monoxide diffusing capacity (DLCo)], which did not deteriorate over 2 years. ${ }^{23}$ However, no long term safety data is available from adults with relation to altered pulmonary function. Approval for use with children will need to wait for this information. The fact that it is available as a dry preparation, which does not require a refrigerator, may offer great advantages in tropical parts of the world if cost-effective preparations can be prepared. ${ }^{21}$

\section{Intensive diabetes treatment}

Intensive management of diabetes includes administering insulin calculated to meet basal and mealtime requirements and frequent blood glucose measurements in order to adjust insulin doses, also offering the possibility of making adjustments to account for the rate at which the carbohydrates from meals and snacks are consumed during physical exercise. This type of management is known as basal-bolus dosing and is currently the most recommended strategy. ${ }^{21}$

\section{Basal-bolus regime}

The models which best provide for insulin delivery in a basal-bolus dosing scheme are those treatment regimes that employ insulin infusion pumps, although basal-bolus treatment can also be given using injections. They are best when employing a long-acting analog as basal insulin and a rapid or short-acting insulin for mealtimes (bolus). Other regimes of basal insulin include multiple doses of NPH/lente or NPH/ lente administered before sleep, combined with daytime bolus of rapid or short-acting insulin. In basal-bolus regimes the insulin dosage calculation varies according to age, weight and duration of diabetes. In general, the distribution of the total daily dose is close to $50 \%$ basal and $50 \%$ prandial. The most flexible and most physiological means of covering mealtimes is to use the carbohydrate-insulin ratio, which is a calculation that is based on the insulin sensitivity of each individual. The majority of individuals require a carbohydrate to insulin ratio of 10-15 g per unit of insulin, but often prepubescent children require less and adolescents require a greater number of units per gram of carbohydrate. Prandial insulin can be adjusted testing blood glucose levels 2-3 h after meals and comparing this with the preprandial level. The difference between the preprandial glucose and the PPG should be less than 20-30 $\mathrm{mg} / \mathrm{dL}(1-1.5 \mathrm{mmol} / \mathrm{L})$ if the insulin dosage is correct. Basal insulin dosage is best adjusted by means of frequent glycemia assays (every $2 \mathrm{~h}$ ) during a period of fasting of at least $6 \mathrm{~h}$.

Injection-based basal-bolus regimes allow greater flexibility in terms of the times of meals, but the regime often results in an increased number of injections per day. Furthermore, basal-bolus treatment can be complicated for children who are reluctant to inject themselves at school because it sets them apart from their peers. ${ }^{21}$
In addition to the mealtime bolus, individuals on basalbolus insulin regimes can also apply a corrective bolus when their blood glucose level is above the target recommended by their physician. The American Diabetes Association (ADA) and other international organizations have published guidelines for target glycemic ranges by age. ${ }^{4}$ The corrective bolus is based on the number of units ( $\mathrm{mmol} / \mathrm{L}$ or $\mathrm{mg} / \mathrm{dL}$ ) by which glycemia is reduced after administrating one unit of rapidacting insulin. This depends on insulin sensitivity. One method of calculating the correction dose for a patient is known as the 1500 rule. According to this rule, the correction dose can be calculated by dividing 1500 (or 83 in the SI system) by the total daily dose (TDD) of insulin. This rule works best for people using regular insulin as their bolus insulin. More recently, 1800 (100 SI) was proposed as being the ideal numerator to be used with this rule when the individual is using a rapid-acting insulin analog. Numerators between 1600 (89 SI) and 2200 (122 SI) were proposed for use when the basalbolus ratio is greater than or equal to 1 . Numerators below 1800 (100 SI) are recommended when basal insulin makes up less than $50 \%$ of the total daily dose and numerators greater than 1800 (100 SI) are recommended when basal insulin accounts for more than $50 \%$ of the total daily dose. ${ }^{24}$ Except during disease, an interval of 2-3 $\mathrm{h}$ should be allowed between each correction bolus in order to avoid summation of the insulin doses, which could result in hypoglycemia.

Irrespective of the insulin regime, physical exercise calls for adjustments to insulin dosage and/or additional carbohydrate doses. The dose of insulin and carbohydrate intake before, during and after exercise, are heavily dependent on the type, intensity and duration of physical activity. If the blood glucose level prior to exercise is below $130 \mathrm{mg} / \mathrm{dL}(7,2 \mathrm{mmol} /$ L), a snack containing 15-30 g of carbohydrates will reduce the risk of hypoglycemia in a period of 1 to $2 \mathrm{~h}$ of moderate exercise. ${ }^{25}$ For users of insulin pumps, suspending the basal rate during exercise for up to $120 \mathrm{~min}$ reduces the risk of hypoglycemia during exercise. ${ }^{26}$ For those who use injection regimes, the risk of nocturnal hypoglycemia can be reduced if low blood glucose levels during exercise are treated with $30 \mathrm{~g}$ of carbohydrates, the bolus dose is reduced for the meal after exercise and the evening snack is increased if blood glucose levels before going to sleep are below $130 \mathrm{mg} / \mathrm{dL}$ ( $7.2 \mathrm{mmol} /$ L). ${ }^{27}$ Greater adjustments are necessary for highly active young athletes, who may need to reduce their insulin regime by as much as $50 \%$ on days of much physical activity.

\section{Continuous subcutaneous insulin infusion pumps}

Continuous subcutaneous insulin infusion (CSII) pumps offer a more physiological insulin delivery because, in comparison with the other options currently available, they most closely simulate insulin production by the pancreatic beta cells, with prandial bolus superimposed on the continuous feed (Figure 1). The CSII system has been shown to improve the glycemic control of children and adolescents with T1DM, with 
a concomitant reduction in severe hypoglycemic episodes. 28,29

Using rapid acting analogs is superior to regular insulin for CSII, with reduced rates of postprandial hyperglycemia and nocturnal hypoglycemia. ${ }^{30,31}$ Insulin lispro, aspart, and glulisine are all approved for use with CSII in the United States and many other countries. ${ }^{32}$ Interrupting the basal insulin rate (pausing or disconnecting the pump) during physical exercise has proven effective for reducing hypoglycemia in children with T1DM. ${ }^{26}$ Although there is no evidence that treatment with insulin pumps results in sustained improvements in glycemic control with young children less than 6 years old ${ }^{30}$ the risks are $10 w^{33}$ and parental satisfaction with the increased flexibility appears to be elevated, making CSII a useful option for younger children. ${ }^{34}$

The newest generation of smart pumps can preprogram prandial or correctional bolus doses based on the insulin-tocarbohydrate ratio, maintaining the bolus insulin and insulin sensitivity useable. Smart pumps also offer the option of delivering the prandial bolus in a square or extended wave or in combined bolus to better cover mixed meals, which may take longer to absorb, or for diabetes patients who suffer from gastroparesis. This increases the convenience of more sophisticated insulin profiles for all CSII users and increases CSII treatment safety with younger children. The variability of basal infusion rate profiles, in combination with the ability to make very small adjustments (0.025-0.05 U/h of insulin), make it possible to reduce hypoglycemia episodes, particularly during the night. The standard hourly tests of basal levels and prandial insulin demands vary with age and the time of day; young children require lower basal rates. ${ }^{21}$ The ratio of insulin to carbohydrates (the quantity of insulin per gram of carbohydrates) is generally most elevated in the morning and lower at a lunch and dinner. Adolescents have reduced

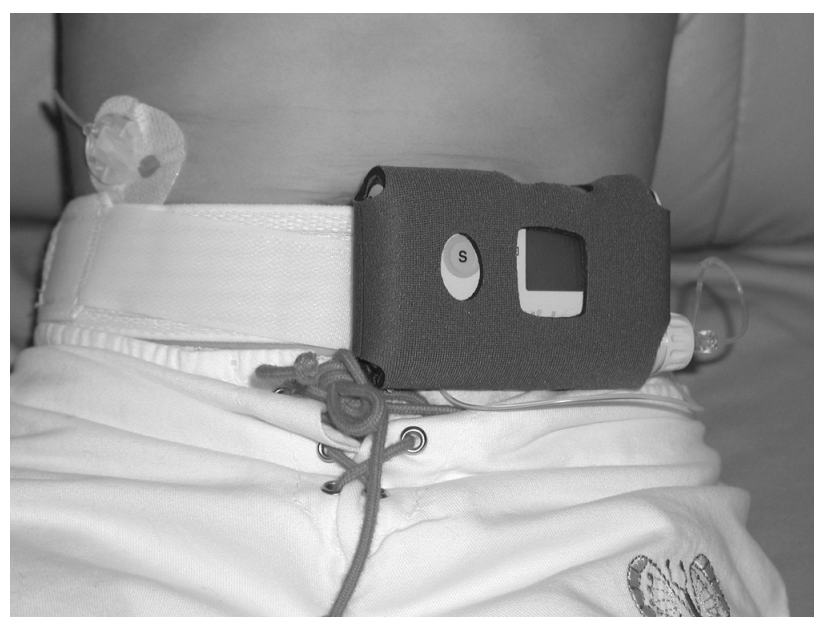

Figure 1 - Insulin infusion pump fitted to the waist of an 11-yearold girl. The subcutaneous cannula can be observed on the left above the belt insulin sensitivity in the early morning (the dawn phenomenon), while younger children require basal insulin frequently during the night, before midnight. ${ }^{29,35}$ Not administering the mealtime bolus appears to be the major cause of less than ideal glycemic control among children and adolescents with T1DM on CSII treatment. ${ }^{36}$

\section{Continuous glucose control by subcutaneous monitoring}

The continuous glucose monitoring system (CGMS) is a powerful tool for improving the intensive management of diabetes (Figure 2). Despite the results of the DCCT, around $70 \%$ of young T1DM patients continue to be incapable of achieving their recommended glycemic targets. ${ }^{37-39}$ Hypoglycemia is more common among children than adults ${ }^{2}$ and continues to be the principal impediment to achieving the glycemic control that is aimed at. Continuous sensors may be of a type which provide glycemic data when the patient returns to the laboratory where the monitor was installed or they can be real time. Real-time continuous glycemia sensors (not yet available in Brazil) have the potential of revolutionizing T1DM treatment, providing patients with information which relates to PPG and nocturnal glycemia, which is rarely available with conventional capillary glycemia monitoring. There are currently three instruments approved for use in the United States by the FDA and which provide hundreds of glycemia readings per day and display the information in real-time.

However, just one device is approved to use with children less than 18 years old. ${ }^{40}$ Devices are equipped with alarms to warn of glycemic levels outside of the target range and also of hypoglycemia and hyperglycemia. These CGMS devices provide patients with an immediate breakdown of their response to nutrition, exercise and insulin doses, often resulting in behavioral changes. ${ }^{41}$ Several insulin pumps of the most recent generation have incorporated programming compatible with continual glycemia monitoring, and it is anticipated that eventually they will have internal algorithms that automatically adjust the insulin infusion rate, based on the glycemia level and rates of change. Such closed-loop devices would probably reduce user error, making treatment with pumps a safe and viable option in a larger proportion of the population.

Furthermore, the information obtained from the use of continuous glycemia monitoring in research studies can be applied to general practice even if this technology does not become widely available for many years. For example, the clinical experience of some authors with continuous glucose sensors has demonstrated that, in children, postprandial hyperglycemia often lasts for 2-3 $\mathrm{h}$ after the meal and that peak activity of a rapid-analog can be combined with the meal when the dose is administered 20-30 minutes before eating. Clinical experience with CGMS has also led to the recommendation of more frequent use of quadruple one double bolus 


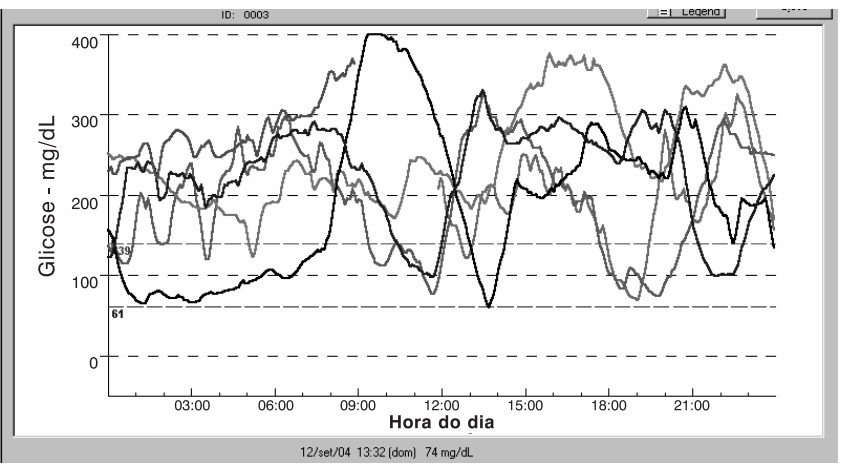

Figure 2 - Records of subcutaneous glucose monitored over 4 days (MINIMED) in an 11-year old child. Postprandial hyperglycemia can be observed at several points

with mixed meals for children who use CSII, in order to greater reduce glycemic increases. ${ }^{21}$

\section{Future insulin treatments}

Other routes of insulin administration are being investigated, including dermal, buccal and oral insulin. Buccal insulin is sprayed into the cheek where it is absorbed by the buccal mucosa and may be an alternative route to subcutaneous or inhaled insulin to control PPG increases. ${ }^{21}$

Oral insulin is another alternative method of insulin administration that is still in the early stages of development. The oral route of insulin delivery has advantages due to the portalhepatic absorption route. To our knowledge, only clinical experiments with prevention (but no therapeutic experiments) have been published on human beings to date. The challenge will be to develop a formulation that is stable for oral insulin delivery. Potential carriers for oral route insulin delivery are being studied with promising results in diabetic rats. ${ }^{21}$

\section{Conclusions}

The DCCT demonstrated the efficacy of intensive management of diabetes mellitus for reducing microvascular complications of T1DM. However, the DCCT also reported a clear inverse correlation between $\mathrm{HbA} 1 \mathrm{c}$ levels and the occurrence of severe hypoglycemia. Currently, the majority of national and international diabetes organizations recommend the use of basal-bolus insulin regimes. The more widespread use of insulin pump treatments and the introduction of insulin analogs have provided a more physiological approximation to insulin replacement in children and adolescents with T1DM. In January 2005, the ADA published age-specific guidelines on $\mathrm{HbA} 1 \mathrm{c}$ and new glycemic targets for children similar to those in other guidelines published by the association and the diabetes society. However, it is estimated that just approximately $30 \%$ of diabetic children in the United States achieve these new ADA objectives. Hypoglycemia is the principal limiting factor to maintaining intensive glycemic control, especially in young children who are at risk of developing compromised cognitive functions if they suffer repeated hypoglycemic episodes. The effective application of new technologies to diabetes, such as continuous subcutaneous glucose monitoring and the closed-loop system, offer hope that the lower glycemic targets can be met without increasing the number of episodes of hypoglycemia.

\section{References}

1. The effect of intensive treatment of diabetes on the development and progression of long-term complications in insulin-dependent diabetes mellitus. The Diabetes Control and Complications Trial Research Group. N Engl J Med. 1993;329:977-86.

2. Effect of intensive diabetes treatment on the development and progression of long-term complications in adolescents with insulin-dependent diabetes mellitus: Diabetes Control and Complications Trial. Diabetes Control and Complications Trial Research Group. J Pediatr. 1994;125:177-88.

3. White NH, Cleary PA, Dahms W, Goldstein D, Malone J, Tamborlane WV, et al. Beneficial effects of intensive therapy of diabetes during adolescence: outcomes after the conclusion of the Diabetes Control and Complications Trial (DCCT). J Pediatr. 2001;139:804-12.

4. American Diabetes Association. Standards of Medical Care in Diabetes. Diabetes Care. 2007;30(Suppl 1):S4-S36.

5. Sociedade Brasileira de Diabetes. Uso da insulina no tratamento do diabetes mellitus tipo 1. In: Sociedade Brasileira de Diabetes. Tratamento e acompanhamento do diabetes mellitus. Diretrizes da Sociedade Brasileira de Diabetes. http://www.diabetes.org.br/educacao/docs/diretrizes.pdf. Access: 20/08/2007. 
6. Chase P. Understanding diabetes. 11th ed. Denver: Children's Diabetes Foundation at Denver; 2006.

7. Danne $T$, Mortensen HB, Hougaard $P$, Lynggaard $H$, Aanstoot $\mathrm{HJ}$, Chiarelli $\mathrm{F}$, et al. Persistent differences among centers over 3 years in glycemic control and hypoglycemia in a study of 3,805 children and adolescents with type 1 diabetes from the Hvidore Study Group. Diabetes Care. 2001;24:1342-7.

8. Plank J, Siebenhofer A, Berghold A, Jeitler K, Horvath K, Mrak P, et al. Systematic review and meta-analysis of short-acting insulin analogues in patients with diabetes mellitus. Arch Intern Med. 2005; 165:1337-44.

9. Siebenhofer A, Plank J, Berghold A, Jeitler K, Horvath K, Narath $M$, et al. Short acting insulin analogues versus regular human insulin in patients with diabetes mellitus. Cochrane Database of Syst Rev; 2006. Issue 2. Art. No.: CD003287.

10. Gough SC. A review of human and analogue insulin trials. Diabetes Res Clin Pract. 2007:77:1-15.

11. Jovanovic L, Giammattei J, Acquistapace M, Bornstein K, Sommermann E, Pettitt DJ. Efficacy comparison between preprandial and postprandial insulin aspart administration with dose adjustment for unpredictable meal size. Clin Ther. 2004; 26:1492-7.

12. Ceriello A. Postprandial hyperglycemia and diabetes complications: is it time to treat? Diabetes. 2005;54:1-7.

13. Glucose tolerance and mortality: comparison of WHO and American Diabetes Association diagnostic criteria. The DECODE Study Group. European Diabetes Epidemiology Group. Diabetes Epidemiology: Collaborative analysis of Diagnostic criteria in Europe. Lancet. 1999;354:617-21.

14. Chiasson JL, Josse RG, Gomis R, Hanefeld M, Karasik A, Laakso $M$, et al. Acarbose treatment and the risk of cardiovascular disease and hypertension in patients with impaired glucose tolerance: the STOP-NIDDM trial. JAMA. 2003; 290:486-94.

15. Jackson A, Ternand C, Brunzell C, Kleinschmidt T, Dew D, Milla $C$, et al. Insulin glargine improves hemoglobin $A 1 c$ in children and adolescents with poorly controlled type 1 diabetes. Pediatr Diabetes. 2003;4:64-9.

16. Fiallo-Scharer R, Horner B, McFann K, Walravens P, Chase HP. Mixing rapid-acting insulin analogues with insulin glargine in children with type 1 diabetes mellitus. J Pediatr. 2006; 148:481-4.

17. Kaplan W, Rodriguez LM, Smith OE, Haymond MW, Heptulla RA. Effects of mixing glargine and short-acting insulin analogs on glucose control. Diabetes Care. 2004;27:2739-40.

18. Plank J, Bodenlenz M, Sinner F, Magnes C, Görzer E, Regittnig W, et al. A double-blind, randomized, dose-response study investigating the pharmacodynamic and pharmacokinetic properties of the long-acting insulin analog detemir. Diabetes Care. 2005;28:1107-12.

19. Soran $\mathrm{H}$, Younis $\mathrm{N}$. Insulin detemir: a new basal insulin analogue. Diabetes Obes Metab. 2006;8:26-30.

20. Robertson KJ, Schoenle E, Gucev Z, Mordhorst L, Gall MA, Ludvigsson J. Insulin detemir compared with NPH insulin in children and adolescents with Type 1 diabetes. Diabet Med. 2007; 24:27-34.

21. Steck AK, Klingensmith GJ, Fiallo-Scharer R. Recent advances in insulin treatment of children. Pediatr Diabetes. 2007;8:4956.
22. Ceglia L, Lau J, Pittas AG. Meta-analysis: efficacy and safety of inhaled insulin therapy in adults with diabetes mellitus. Ann Intern Med. 2006;145:665-75.

23. Skyler JS, Jovanovic L, Klioze S, Reis J, Duggan W; Inhaled Human Insulin Type 1 Diabetes Study Group. Two-year safety and efficacy of inhaled human insulin (Exubera) in adult patients with type 1 diabetes. Diabetes Care. 2007;30:579-85.

24. Walsh J, Roberts R, Bailey T, Varma C. Using insulin. San Diego: Torrey Pines; 2003.

25. Tansey MJ, Tsalikian E, Beck RW, Mauras N, Buckingham BA, Weinzimer SA, et al. The effects of aerobic exercise on glucose and counterregulatory hormone concentrations in children with type 1 diabetes. Diabetes Care. 2006;29:20-5.

26. Diabetes Research in Children Network (DirecNet) Study Group, Tsalikian E, Kollman C, Tamborlane WB, Beck RW, Fiallo-Scharer $R$, et al. Prevention of hypoglycemia during exercise in children with type 1 diabetes by suspending basal insulin. Diabetes Care. 2006;29:2200-4.

27. Tsalikian E, Mauras N, Beck RW, Tamborlane WV, Janz KF, Chase HP, et al. Impact of exercise on overnight glycemic control in children with type 1 diabetes mellitus. J Pediatr. 2005; 147:528-34.

28. Jeha GS, Karaviti LP, Anderson B, Smith EO, Donaldson S, McGirk TS, et al. Insulin pump therapy in preschool children with type 1 diabetes mellitus improves glycemic control and decreases glucose excursions and the risk of hypoglycemia. Diabetes Technol Ther. 2005; 7:876-84.

29. Boland EA, Grey M, Oesterle A, Fredrickson L, Tamborlane WV. Continuous subcutaneous insulin infusion. A new way to lower risk of severe hypoglycemia, improve metabolic control, and enhance coping in adolescents with type 1 diabetes. Diabetes Care. 1999;22:1779-84.

30. DiMeglio LA, Pottorff TM, Boyd SR, France L, Fineberg N, Eugster EA. A randomized, controlled study of insulin pump therapy in diabetic preschoolers. J Pediatr. 2004;145:380-4.

31. Zinman B, Tildesley $H$, Chiasson JL, Tsui $E$, Strack T. Insulin lispro in CSII: results of a double-blind crossover study. Diabetes. 1997; 46:440-3.

32. Hoogma RP, Schumicki D. Safety of insulin glulisine when given by continuous subcutaneous infusion using an external pump in patients with type 1 diabetes. Horm Metab Res. 2006;38:42933.

33. Wilson DM, Buckingham BA, Kunselman EL, Sullivan MM, Paguntalan HU, Gitelman SE. A two-center randomized controlled feasibility trial of insulin pump therapy in young children with diabetes. Diabetes Care. 2005;28:15-9.

34. Eugster EA, Francis G; Lawson-Wilkins Drug and Therapeutics Committee. Position statement: Continuous subcutaneous insulin infusion in very young children with type 1 diabetes. Pediatrics. 2006;118:e1244-e49.

35. Danne T, Battelino T, Kordonouri O, Hanas R, Klinkert C, Ludvigson J, et al. A cross-sectional international survey of continuous subcutaneous insulin infusion in 377 children and adolescents with type 1 diabetes mellitus from 10 countries. Pediatr Diabetes. 2005;6:193-8.

36. Burdick J, Chase HP, Slover RH, Knievel K, Scrimgeour L, Maniatis $A K$, et al. Missed insulin meal boluses and elevated hemoglobin A1c levels in children receiving insulin pump therapy. Pediatrics. 2004;113(3 Pt 1):e221-4. 
37. Rosilio M, Cotton JB, Wieliczko MC, Gendrault B, Carel JC, Couvaras $\mathrm{O}$, et al. Factors associated with glycemic control. A cross-sectional nationwide study in 2,579 French children with type 1 diabetes. The French Pediatric Diabetes Group. Diabetes Care. 1998;21:1146-53.

38. Mortensen HB, Hougaard P. Comparison of metabolic control in a cross-sectional study of 2,873 children and adolescents with IDDM from 18 countries. The Hvidore Study Group on Childhood Diabetes. Diabetes Care. 1997;20:714-20.

39. Scottish Study Group for the Care of the Young Diabetic. Factors influencing glycemic control in young people with type 1 diabetes in Scotland: a population-based study (DIABAUD2). Diabetes Care. 2001;24:239-44.

40. U.S. Food and Drug Administration, Center for Devices and Radiological Health. Summary of safety and effectiveness data. http://www.fda.gov/cdrh/PDF/p980022s015b.pdf. Access: 20/ $08 / 2007$.
41. Garg S, Jovanovic L. Relationship of fasting and hourly blood glucose levels to HbA1c values: safety, accuracy, and improvements in glucose profiles obtained using a 7-day continuous glucose sensor. Diabetes Care. 2006;29:2644-9.

Correspondence:

Helena Schmid

Fundação Federal Faculdade de Ciências Médicas de Porto

Alegre

Departamento de Medicina Interna - Endocrinologia

Rua Sarmento Leite, 245

CEP 90050-170 - Porto Alegre, RS - Brazil

Tel.: +55 (51) 3214.8181

Fax: +55 (51) 3226.7913

E-mail: neurodiabetes@terra.com.br 